\title{
Reduction Energy of 1 M Aqueous Ruthenium(III)Hexaammine in the Gas Phase: A Route Towards Establishing an Absolute Electrochemical Scale
}

Ryan D. Leib, William A. Donald, Jeremy T. O'Brien, Matthew F. Bush and Evan R. Williams* Department of Chemistry, University of California, Berkeley, CA 94720-1460

\section{Supplemental Information}

\section{Ionization and Reduction:}

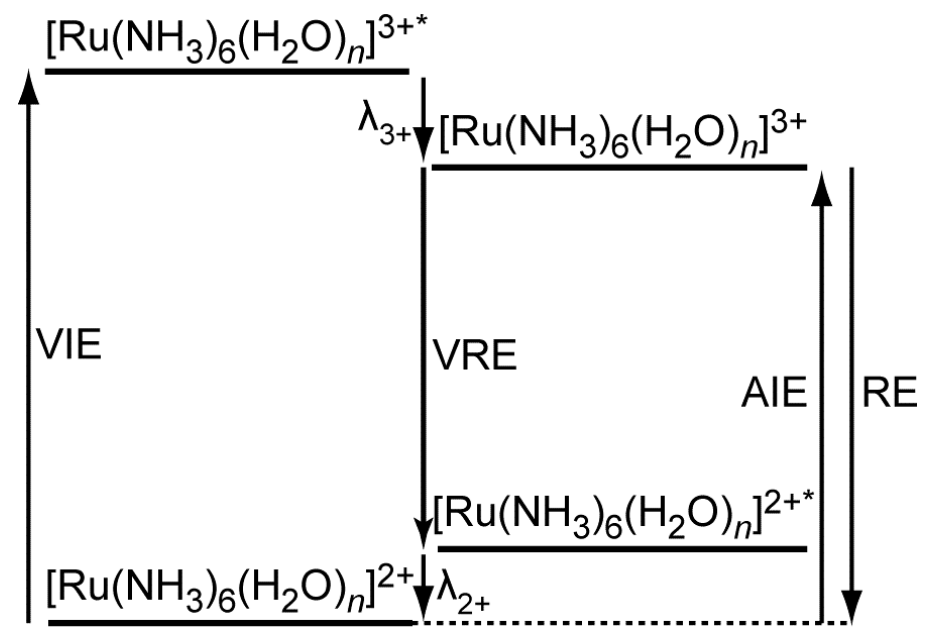

Supplemental Figure 1. Energy level diagram for the ionization and reduction of hydrated rutheniumhexaammine cluster ions in the gas phase. The adiabatic ionization energy (AIE), vertical ionization energy (VIE), vertical recombination energy (VRE), recombination energy (RE) and the solvent reorganization energy of the trivalent $\left(\lambda_{3+}\right)$ and divalent $\left(\lambda_{2+}\right)$ clusters are shown.

The vertical ionization energy (VIE) of a hydrated cluster is greater than the adiabatic ionization energy (AIE) by a value corresponding to the solvent reorganization energy of the trivalent cluster $\left(\lambda_{3_{+}}\right)$(Supplemental Fig. 1). Although EC may be a vertical process, the experimentally determined recombination energy (RE) should closely approximate the AIE of the reduced species because the time between EC and the start of ion detection is between 0.375 and $40.4 \mathrm{~ms}$ (depending on when EC occurs) which is significantly longer than the time needed for solvent reorganization. Energy released by solvent reorganization of the divalent cluster $\left(\lambda_{2+}\right)$ after EC will appear as internal energy and will contribute to the observed water evaporation 
from the cluster. For $\mathrm{Ca}\left(\mathrm{H}_{2} \mathrm{O}\right)_{47}{ }^{2+}$, increasing the time between $\mathrm{EC}$ and ion detection by $50 \mathrm{~ms}$ results in no additional loss of water. This indicates that solvent reorganization must be complete on the time scale of these experiments.

\section{Solvation energy calculations:}

A limitation of solvation models is the difficulty of accurately modeling the effects of solvent-ion interactions at short distances where the solvent properties are different from the bulk. ${ }^{1}$ Previous computational approaches have used either implicit solvation models that use bulk properties, ${ }^{2}$ or have treated the solute and what is believed to be the first and second solvation shells explicitly with quantum mechanics and then used classical electrostatic models to account for long-range effects. ${ }^{2 \mathrm{~m}-\mathrm{o}}$ The latter approach can greatly enhance the accuracy of calculating absolute electrochemical potentials. ${ }^{2 \mathrm{~m}}$ The reduction potentials of the $\mathrm{Mn}^{3+/ 2+}$ and $\mathrm{Fe}^{3+/ 2+}$ couples were calculated using density functional theory (DFT) and polarizable continuum model (PCM) treating either 6 or 18 water molecules explicitly. ${ }^{2 \mathrm{~m}}$ With 6 solvent molecules treated explicitly with DFT, the reduction potentials were about $1 \mathrm{~V}$ higher than when 18 water molecules were explicitly included. This indicates that including just a single solvation shell explicitly is insufficient. Results from DFT and conductor-like solvation model (COSMO) calculations of the redox potentials of fourth-period transition metals indicate that inclusion of two solvation spheres (18 water molecules) was necessary to reproduce experimental values to within an average error of $0.29 \mathrm{~V} .^{20}$

A key advantage of our approach to determining an absolute redox potential is that our experimental measurements include the effects of solvent on reduction energies well past two solvation shells (61 solvent molecules). Thus, these measurements account for ion-solute interactions at shorter distances that have been shown to be difficult to determine 
computationally. ${ }^{1}$ Continuum models, which use bulk solvent properties are more accurate at longer distances. ${ }^{1}$ Thus, by combining our measurements with a continuum model, it may be possible to obtain a more accurate absolute potential.

Here, we use a modified Born equation (1), a simple continuum model, to determine the solvation energy at a given charge state, $\mathrm{E}_{\text {solv }}$, and relate our measured gas-phase reduction potentials of the clusters to solution-phase reduction potentials:

$\Delta \mathrm{G}=-\frac{z^{2} e^{2}}{8 \pi \varepsilon_{0} R_{s}}\left(1-\varepsilon^{-1}\right) \times\left(n+a_{i}+6 a_{a m}\right)^{-1 / 3}=\mathrm{E}_{s o l v}$

where $z e$ is the charge, $n$ is the number of water molecules, $R_{s}$ is the size-exclusion radius of a water molecule, $\varepsilon_{o}$ is the vacuum permittivity and $\varepsilon$ is the dielectric constant of the solvent, $a_{a m}$ and $a_{i}$ are normalizing factors that relate the size of an ammonia molecule and an ion, respectively, to that of a water molecule. Values used for these parameters are given in Supplemental Table 1.

Supplemental Table 1. Parameters used in calculation of cluster solvation energies.

\begin{tabular}{ccccccc|c}
$z$ & $R_{s} / \AA$ & $\varepsilon$ & $n$ & $a_{a m}$ & $a_{i}$ & $\mathrm{E}_{\text {solv }} / \mathrm{eV}$ & \multicolumn{1}{c}{$\Delta \mathrm{E}_{\text {solv }} / \mathrm{eV}$} \\
\hline $3+$ & 1.98 & 3.1 & 55 & 1.04 & 0.04 & -5.6 & -3.1 \\
$2+$ & 1.98 & 3.1 & 55 & 1.04 & 0.13 & -2.5 &
\end{tabular}

A value of $R_{s}=1.98 \AA$ is obtained from the density of hexagonal ice at $0{ }^{\circ} \mathrm{C}(0.9167$ $\left.\mathrm{g} / \mathrm{cm}^{3}\right)^{3 \mathrm{a}}$. The density of hexagonal ice varies with temperature. At $-180{ }^{\circ} \mathrm{C}$, the density is $0.9340 \mathrm{~g} / \mathrm{cm}^{3},{ }^{3 a}$ which corresponds to an $R_{s}$ of $1.97 \AA$. This difference decreases the resulting value of $\Delta \mathrm{E}_{\text {solv }}$ by $0.1 \mathrm{eV}$. The density of water at $0{ }^{\circ} \mathrm{C}\left(0.9998 \mathrm{~g} / \mathrm{cm}^{3}\right)^{3 \mathrm{~b}}$ and supercooled water at $-30{ }^{\circ} \mathrm{C}\left(0.9839 \mathrm{~g} / \mathrm{cm}^{3}\right)^{3 \mathrm{~b}}$ corresponds to $R_{s}$ values of 1.93 and $1.94 \AA$, respectively; these values result in a $\Delta \mathrm{E}_{\text {solv }}$ of $-3.2 \mathrm{eV}$. The $R_{s}$ values obtained from the density of ice and water are similar to the value derived from photoelectron spectroscopy experiments of solvated electrons (1.95 
$\AA),{ }^{4}$ which result in a $\Delta \mathrm{E}_{\text {solv }}$ of $-3.2 \mathrm{eV}$. We conclude that the Born solvation energy correction is relatively insensitive to the value of $R_{s}$ over this range.

The Born solvation energy correction depends on the value of the dielectric constant $(\varepsilon)$ of water which is a function of temperature. ${ }^{5 \mathrm{a}}$ This value at $0 \mathrm{~K}$ is estimated as the highfrequency permittivity of ice at $0 \mathrm{~K} \cdot{ }^{5 a, b}$ A value of $3.1^{5}$ is used because the reduction energy is referenced to $0 \mathrm{~K}$. The dielectric constant has been modeled as a function of temperature. ${ }^{5 \mathrm{a}}$ Between 0 and $30 \mathrm{~K}$, this value does not change but rapidly increases to a value of $\sim 275$ at $50 \mathrm{~K}$. The permittivity gradually decreases to $\sim 90$ at $273 \mathrm{~K}$. The dielectric constant of ice at $273.15 \mathrm{~K}$ is $91.5{ }^{6}$ The calculated $\Delta \mathrm{E}_{\text {solv }}$ is insensitive to the dielectric constant for values above roughly 20. Using the dielectric of ice at $-57{ }^{\circ} \mathrm{C}(114)^{6}$ or that of liquid water at room temperature (80), the $\Delta \mathrm{E}_{\text {solv }}$ is calculated to be $-4.6 \mathrm{eV}$; a value of $\varepsilon=20$ results in a $\Delta \mathrm{E}_{\text {solv }}$ of $-4.4 \mathrm{eV}$. A value of $\Delta \mathrm{E}_{\text {solv }}$ at $298 \mathrm{~K}$ is more physically relevant for comparison to solution-phase values. Subsequent work more directly relating the reduction energy obtained with this approach to those measured in solution will be reported elsewhere.

The values of $a_{a m}$ and $a_{i}$ were obtained from the density of solid ammonia $\left(0.834 \mathrm{~g} / \mathrm{cm}^{3}\right),{ }^{7}$ and the ionic radius of $\mathrm{Ru}^{3+}(0.68 \AA),{ }^{8}$ respectively. The ionic radius for $\mathrm{Ru}^{2+}$ was estimated to be between that of $\mathrm{Pd}^{2+}$ and $\mathrm{Sr}^{2+}(0.86 \AA$ and $1.18 \AA$, respectively, for coordination numbers of six). ${ }^{8}$ Note that $\left[\mathrm{n}+6 a_{a m}\right] \gg>a_{i}$ for both divalent and trivalent ruthenium cations, and that the corresponding ionic volume factors do not contribute any significant amount to the final calculated solvation energy.

(1) (a) Cramer, C. J.; Truhlar, D. G. Chem. Rev. 1999, 99, 2161-2200. (b) Tomasi, J.; Persico, M. Chem. Rev. 1994, 94, 2027-2094. (c) Kelly, C. P.; Cramer, C. J.; Truhlar, D. G. J. Chem. Theory and Comput. 2005, 1, 1133-1152.

(2) (a) Torres, R. A.; Lovell, T.; Noodleman, L.; Case, D. A. J. Am. Chem. Soc. 2003, 125, 1923-1936. (b) Mouesca, J.; Chen, J. L.; Noodleman, L.; Bashford, D.; Case, D. A. J. Am. Chem. Soc. 1994, 116, 11898-11914. (c) Baik, M.; Schauer, C. K.; Ziegler, T. J. Am. Chem. Soc. 2002, 
124, 11167-11181. (d) Wheeler, R. A. J. Am. Chem. Soc. 1994, 116, 11048-11051. (e) Konecny, R.; Li, J.; Fisher, C. L.; Dillet, V.; Bashford, D.; Noodleman, L. Inorg. Chem. 1999, 38, 940-950. (f) Li, J.; Nelson, M. R.; Peng, C. Y.; Bashford, D.; Noodleman, L. J. Phys. Chem. A 1998, 102, 6311-6324. (g) Li, J.; Fisher, C. L.; Konecny, R.; Bashford, D.; Noodleman, L. Inorg. Chem. 1999, 38, 929-939. (h) Winget, P.; Weber, E. J.; Cramer, C. J.; Truhlar, D. G. Phys. Chem. Chem. Phys. 2000, 2, 1231-1239. (i) Kettle, L. J.; Bates, S. P.; Mount, A. R. Phys. Chem. Chem. Phys. 2000, 2, 195-201. (j) Baik, M.; Ziegler, T.; Schauer, C. K. J. Am. Chem. Soc. 2000, 122, 9143-9154. (k) Reynolds, C. A. Int. J. Quantum Chem. 1995, 56, 677-687. (1) Raymond, K. S.; Grafton, A. K.; Wheeler, R. A. J. Phys. Chem. B 1997, 101, 623-631. (m) Li, J.; Fisher, C. L.; Chen, J. L.; Bashford, D.; Noodleman, L. Inorg. Chem. 1996, 35, 4694-4702. (n) Tsushima, S.; Wahlgren, U.; Grenthe, I. J. Phys. Chem. A 2006, 110, 9175-9182. (o) Uudsemaa, M.; Tamm, T. J. Phys. Chem. A 2003, 107, 9997-10003.

(3) (a) Eisenberg, D.; Kauzmann, W. "The Structure and Properties of Water" Oxford, Oxford, 1969. (b) Hare, D. E.; Sorensen, C. M. J. Chem. Phys. 1987, 87, 4840-4845.

(4) Coe, J. V.; Lee, G. H.; Eaton, J. G.; Arnold, S. T.; Sarkas, H. W.; Bowen, K. H.; Ludewigt, C.; Haberland, H.; Worsnop, D. R. J. Chem. Phys. 1990, 92, 3980-3982.

(5) (a) Barkema, G. T.; Boer, J. J. Chem. Phys. 1993, 99, 2059-2067. (b) Gough, S. R. Can. J. Chem. 1972, 50, 3046-3051. (c) Warren, S. G. Appl. Opt. 1984, 23, 1206-1225. (d) Nagle, J. F. Chem. Phys. 1979, 43, 317-328.

(6) Hobbs, M. E.; Jhon, M. S.; Eyring, H. Proc. Nat. Acad. Sci. USA 1966, 56, 31-38.

(7) Olovsson, I.; Templeton, D. H. Acta Cryst. 1959, 12, 832-836.

(8) Shannon, R. D. Acta Cryst. 1976, A32, 751-767. 